\title{
As interfaces entre educação, comunicação e tecnologias através das mídias digitais
}

Evandro Consaltér

Universidade de Passo Fundo

\section{NOGUEIRA, Fernanada; FERREIRA, Arnaldo T (Org.). Comunicação, educação e}

tecnologia: mídias e cultura digital no ideário coletivo. Campinas: Librum, 2017.

Compreender a influência que as mídias exercem sobre a representação do passado e do presente no ideário coletivo é imprescindível para que se possa compreender a realidade em que estamos inseridos e vislumbrar cenários vindouros. Essa discussão ganha ainda mais relevância quanto adentra ao campo da educação, cada vez mais influenciado pela força das novas tecnologias e pela mídia digital. Em face desse contexto, e com a finalidade de estabelecer um diálogo, com base na transversalidade entre três áreas que se correlacionam, desponta a coletânea Comunicação, educação e tecnologia: mídias e cultura digital no ideário coletivo, publicada pela Editora Librum, no final de 2017.

Organizada pela Professora. Dra. Fernanda Nogueira, pesquisadora da Universidade de Granada - Espanha - e da Universidade de Coimbra - Portugal - e pelo Professor Dr. Arnaldo Telles Ferreira, da Universidade do Oeste de Santa Catarina - UNOESC, a coletânea reúne estudos de pesquisadores de diferentes universidades brasileiras e também de pesquisadores de Portugal, da Argentina e da Espanha. A obra está organizada em três partes, reunindo dez capítulos e um posfácio assinado pelos organizadores. A primeira parte da obra é composta por três capítulos, sob a temática "As TICs no contexto educativo contemporâneo". A segunda parte, com a temática "Comunicação, publicidade e memória", está estruturada com mais três capítulos. Por fim, a terceira parte, com quatro capítulos, organiza-se a partir do eixo temático "Imagens e representações da identidade latino-americana no imaginário coletivo".

Abrindo a coletânea, contendo a parte inicial da obra, as autoras Fernanda Nogueira e Pilar lbánez-Cubillas assinam o Capítulo I. Com o título "Estratégias de ensino para o uso das TICs e a importância da formação de 
professores", o texto tem como objetivo tecer uma discussão acerca da importância das TICs nos processos de ensino-aprendizagem, enfatizando o papel das estratégias de ensino com uso das tecnologias com base na Taxonomia de Bloom Digital. Por fim, aborda aspectos voltados à formação de professores com vistas à integração das TICs no cotidiano da sala de aula.

O segundo capítulo da obra tem o título "Contribuições das tecnologias da informação e da comunicação em metodologias alternativas para o uso de animais não-humanizados em aulas experimentais de ciências biológicas". A autoria é das professoras pesquisadoras Neusa Maria John, Tais Lazzari Konflanz e Elisabete Cerutti. As autoras apresentam o uso das TICs como ferramenta alternativa ao uso de animais não-humanos in vivo nas experimentações em ciências biológicas. De acordo com o estudo, essa possibilidade permitiria a promoção de uma aprendizagem motivadora e significativa, uma vez que alguns estudantes se sentem inibidos em utilizar animais in vivo para experiências científicas.

Intitulado "Conectando os professores do ensino superior à cultura digital: as TICs e os seus desafios", o terceiro capítulo tem a autoria dos professores pesquisadores Elisabete Cerutti e Arnaldo Nogaro. Os autores desenvolvem 282 uma abordagem reflexiva acerca da necessidade de inserir, na formação do professor de ensino superior, aspectos relacionados ao uso de recursos digitais em sala de aula de modo que se possa promover uma interação mais efetiva no processo de ensino-aprendizagem. Por fim, Cerutti e Nogaro apontam a importância formação continuada dos docentes de ensino superior de modo que se garanta a apropriação dos saberes didáticos, epistemológicos e técnicos, necessários para a efetivação dessa relação entre educação e tecnologias em sala de aula.

A segunda parte da coletânea dá início ao quarto capítulo cujo título é "Evolución de la publicidade electoral em Argentina desde el retorno delorden institucional: elecciones nacionales 1983-201 1". A autoria do estudo é do professor José Marcos Galone, titular em Teoria da Comunicação Social, da Universidad Nacional de La Plata, da Argentina. Nesse estudo, Galone aborda o impulso ganhado pela revolução das comunicações quando os partidos políticos argentinos foram censurados e obrigados a encerrar suas atividades. Esse marco levou os partidos a incorporar novas regras e estratégias para a comunicação social visando superar os estigmas impostos pelo período 
ditatorial, fazendo com que, desde 1983, todas as campanhas eleitorais fossem desenvolvidas sem ferir a ordem constitucional.

O quinto capítulo é de autoria de Joel Felipe Guindani, Marcela Guimarães e Silva e Tiago Costa Martins. Intitulado "Documentário audiovisual Em algum lugar da memória: do percurso metodológico à possível significação de um modo de viver fronteiriço"; o capítulo aborda o processo de produção do documentário audiovisual Em algum lugar da memória, o qual se apropria de narrativas biográficas para revelar o ofício, em especial no município de São Borja - RS, do Chibeiro do Rio Uriuguai, sujeito histórico, que cruza a fronteira do Brasil com a Argentina para praticar a compra, venda ou troca de produtos.

Da autoria do professor pesquisador Márcio Trevisol, o sexło capítulo faz o fechamento da segunda parte da obra e tem como título "Esfera pública: diagnóstico habermasiano sobre a atuação dos meios de comunicação na formação da opinião pública". Trevisol divide o capítulo em três partes. Na primeira, pontua os principais conceitos de Habermas, expostos na obra Mudança Estrutural da Esfera Pública. Na segunda parte, procede a uma revisão dos argumentos desenvolvidos por Habermas que permitiriam repensar o papel da mídia de massa na colonização da esfera pública. Por fim, estabelece um diálogo com o pensador contemporâneo J. Thompson com a finalidade de compreender a influência midiática na opinião pública.

Abrindo a terceira parte da obra, o sétimo capítulo tem como título "Gênese filosófica da linguagem visual: uma abordagem semiótica". A autora do capítulo é a professora Sílvia Spagnol Simi dos Santos. O estudo objetiva a compreensão de como a imagem e, em consequência a semiótica, está no campo da Filosofia. Para tal, a autora resgata a genealogia da imagem a partir da Grécia Antiga, através de Descartes e Kant, para discutir os fundamentos que embasam teorias de filósofos contemporâneos, com enfoque, principalmente, a questões que envolvem a linguagem, o indivíduo e a sociedade.

O oitavo capítulo é de autoria do professor Paulo Ricardo dos Santos e tem como título "O bandido no cinema brasileiro: do malandro ao marginal". O objetivo do texto é compreender como ocorre a representação do bandido no cinema brasileiro e o contexto da sua personificação. $\bigcirc$ autor tece sua abordagem com base na constituição de dois distintos personagens: a do malandro e a do marginal. Conforme o autor, o malandro permeia a 
sociedade brasileira e é uma figura facilmente identificada em manifestações das mais diversas ordens. Já o marginal não pode ser considerado um análogo ou substituto do malandro, mas um personagem que está à margem da sociedade, cuja existência é indesejada.

De autoria do professor pesquisador Arnaldo Telles Ferreira, o nono capítulo é intitulado "Entre imagens e narrativas: elementos da linguagem fotográfica". $\bigcirc$ estudo é uma análise abrangente da construção da linguagem fotográfica emergente de uma sociedade midiatizada pela criação de uma cultura visual, que carrega representações de ideologias, crenças e, até mesmo, sua própria racionalidade. Conforme o autor, em face desse contexto, a imagem fotográfica exerce um papel ativo como elemento comunicacional de quase todas as manifestações que definem a sociedade moderna.

O décimo capítulo, último da coletânea, tem como título "Representações da tradição na constituição das identidades sulinas: imaginários étnico-culturais no contexto regional". O autor, Ricardo Pavan, tece uma abordagem acerca da formação sociocultural da região Sul do Brasil. Conforme Pavan, essa região sempre esteve permeada pelo sentimento de pertença a grupos de descendentes, em sua maioria, alemães e italianos, e 284 pelo culto às tradições gaúchas. Uma vez que as representações são aceitas e compartilhadas pela comunidade regional, podem ser incorporadas como características de uma determinada população e assumir o papel de matriz cultural de uma sociedade.

Por fim, o conjunto de textos da coletânea Comunicação, Educação e Tecnologia: mídias e cultura digital no ideáriocoletivo constitui-se em um rico material para análise e compreensão das relações que as mídias digitais estabelecem com a área da comunicação e da educação. A obra é uma leitura recomendada para professores e estudantes de licenciatura, bem como para profissionais da comunicação, que se colocam diante do desafio de fazer a integração entre as novas fontes de conhecimento estabelecidas a partir das tecnologias e a prática educativa em seus mais diferentes âmbitos e níveis. Ademais, é possível encontrar o amparo teórico e epistemológico pertinentes para a elaboração de práticas pedagógicas consistentes e didaticamente adequadas para os desafios da docência na atualidade. 
Doutorando Evandro Consaltér

Universidade de Passo Fundo

Programa de Pós-Graduação em Educação Vice Coordenador do Grupo de Estudos e Pesquisas em Educação Superior (GEPES/UPF) Grupo Internacional de Estudos e Pesquisas sobre Educação Superior (GIEPES) da Universidade de Campinas. E-mail: evandroconsalter@gmail.com

Recebido 27 jun. 2018 Aceito 17 ago. 2018 


\section{Normas Gerais de Publicação na Revista Educação em Questão}

1. A Revista Educação em Questão é um periódico trimestral do Centro de Educação e do Programa de Pós-Graduação em Educação da Universidade Federal do Rio Grande do Norte (UFRN). Periódico (on-line) de acesso aberto e submissão sem custos para o(s) autor(es), publica artigos originais e inéditos de Educação, resultantes de pesquisa cientifica, além de resenhas de livros e documentos históricos.

2. $\bigcirc$ artigo em consonância com o que prescrevem estas Normas Gerais é configurado para papel A4, observando as seguintes indicações: digitação em word for windows; margem direita/superior/inferior $2,5 \mathrm{~cm}$; margem esquerda 2,5 cm; fonte Century Gothic no corpo 12, com espaçamento entre linhas 1,5 cm. Nas citações (a partir de quatro linhas), o espaçamento é simples e a fonte, 11 .

3. $\bigcirc$ artigo original e Inédito (português, espanhol, francês e inglês), entre 25 e 30 laudas, deve incluir Resumo em português, espanhol, inglês e francês (para artigo em língua francesa) em torno de 15 (quinze) linhas ou 150 (cento e cinquenta) palavras, com indicação de quatro (4) palavras-chave em cada idioma; o espaçamento entre linhas 1,5 cm e a fonte 12 .

4. No início do artigo, figurará o título em português, inglês e espanhol, antes de cada resumo (negrito e caixa baixa), autoria(s), instituição.

5. $\bigcirc$ título deverá conter, no máximo, 100 (cem) caracteres com espaço.

6. A citação, a partir de quatro linhas, deve ser recuada e seguida do sobrenome do(s) autor(es), ano e página.

7. Escrever o sobrenome dos autores citados no corpo do trabalho. 